doi: 10.32620/oikit.2021.92.12

УДК 004.94+004.4'2

О. В. Полярус, А. В. Лебединський

\title{
Метод, модель та інформаційна технологія визначення сталості інформації при дистанційному контролі стану технічних об’сктів
}

\author{
Харківський національний автомобільно-дорожній університет
}

В інформаційних технологіях доцільним $€$ визначення сталості інформації, тобто спроможність отримувати точну інформацію в умовах, що змінюються. В таких обставинах вхідні процеси описуються нестаціонарними випадковими процесами, у яких значення дисперсії та математичного сподівання змінюється із плином часу. В статті запропоновано модель і метод чисельного визначення сталості інформації (показника сталості) в умовах нестаціонарності вхідних процесів, а також інформаційна технологія, що дозволяє наочно отримувати відомості про сталість конкретної інформації в залежності від рішення про стан технічного об'єкту. Для прикладу в якості такого об'єкту вибрано мостову споруду, а інформація формується на основі сигналів, що описують прогини нижньої частини споруди.

У статті проаналізовано щільності ймовірностей стаціонарних і нестаціонарних процесів прогину мостових споруд для різних видів навантажень. У більшості випадків щільність ймовірностей обох процесів описується гауссівськом законом. Було знайдено залежність сталості інформації від середньоквадратичного значення прогину мостових споруд, а також залежність сталості інформації від середньоквадратичного значення прогину при великих фрлуктуаціях стаціонарних прогинів.

Було розроблено графічний інтерфейс користувача, який дозволяє наочно побачити графрік розподілу щільності ймовірностей прогину у деякій точці мостової споруди, а також визначити чисельно показник сталості інформації, який за визначенням може коливатися від 0 до 1. Наявність мінімального значення показника можна трактувати як відсутність сталості інформації, а максимальне значення показника сталості - наявність сталості інформації.

Зроблено висновки, що даний метод є універсальним і може використовуватися для різних технічних об'єктах в умовах нестаціонарності. Після аналізу графіків залежності показника сталості та середньоквадратичного значення прогину було виявлено, що зі збільшенням середньоквадратичного значення прогину в нестаціонарному процесі при малих фрлуктуаціях стаціонарних прогинів сталість інформації істотно зменшується.

Ключові слова: інформаційна технологія; дистанційний контроль стану технічних об'єктів; сталість інформації; мостові споруди; нестаціонарні процеси.

\section{Вступ}

Вимірювальна інформація, що знімається з багатьох динамічних об'єктів, наприклад, мостових споруд (MC) $є$ важливою для оцінки або прогнозування їх технічного стану. Технічний стан мостової споруди може оцінюватись шляхом визначення коефіцієнту динамічності [1], який $€$ відношенням динамічного та статичного прогинів нижньої горизонтальної частини МС в окремій точці. Як правило, прогини оцінюють при відсутності рухомого транспорту на мосту, але в [2] запропоновано дистанційні методи вимірювання прогинів під час руху автомобілів. Характер навантаження МС в цих умовах $€$ в загальному випадку нестаціонарним випадковим процесом (НВП), що приводить також до нестаціонарності випадкового процесу прогинів, який несе закодовану інформацію про технічний стан споруди. Оцінка технічного стану споруди за реалізаціями НВП є складною процедурою. Найбільш придатні умови для 
розроблення правильних рішень про стан технічного об'єкту досягаються при сталій інфрормації, що отримується від нього. Аналогічна картина спостерігається при навігації автономних мобільних роботів, прив'язка яких до наземного орієнтиру здійснюється за критерієм відмінності параметрів кольоровості орієнтиру та навколишньої місцевості [3]. Якраз для цього випадку в статті проведено моделювання сталості інфрормації. Оцінка сталості інфрормації в соціальних системах приведена в [4]. В [5] досліджується наявність аспектів стійкості в моделі управління інформаційними технологіями. Часто поняття сталості (стійкості) стосується тільки інформаційних систем, а не інфрормації [6].

В окремих роботах, наприклад, в [7] розглядається стійка інформація, що складається з двох різних частин: інформації для сталого розвитку та розвитку стійкої інфрормації (зокрема, створення стійких інформаційних технологій). Стійкість інформації розглядається також як атрибут її неперервного постачання споживачу [8]. Отже, однією з головних проблем існуючих інформаційних технологій $€$ відсутність загальноприйнятих показників, якими можна характеризувати сталість інформації. В статті джерелом інфрормації є природна або технічна система, параметри якої дистанційно вимірюються. Інформація від такої системи $є$ завжди і з точки зору вище зазначених робіт вона $є$ стійкою. Якщо ж параметри зазначеної системи являють собою НВП, то в системі обробки інфрормації важко ввести пороги, перевищення яких означає прийняття якогось конкретного рішення. Нестаціонарність вимірюваних параметрів випадкових процесів еквівалентно нестійкості (несталості) інформації, що викликає розробку нового методу обробки інформації. Дійсно, згідно 3 [9] стійкість означає здатність довго зберігати і виявляти свої властивості. Отже, доцільно організувати обробку інформації таким чином, щоб статистичні характеристики результатів вимірювання змінювались мало.

Метою статті $€$ створення моделі, методу та інформаційної технології визначення сталості інформації при дистанційному контролі мостових споруд.

\section{1. Метод визначення сталості інформації}

Інформація джерела повідомлення в загальному випадку визначається через ентропію [10]

$$
H=\int_{-\infty}^{\infty} p(x) \log _{2} p(x) d x,
$$

де $p(x)$ - закон розподілу (щільність ймовірностей) неперервної величини $x$.

Кількість інформації $I$ визначається як різниця між апріорною та апостеріорною ентропіями. Вважаємо, що в результаті вимірювання $x$ отримана множина реалізацій, що характеризують випадковий процес $\xi(t)$. Якщо процес $\epsilon$ стаціонарним, то закон розподілу $p_{s}(x)$ визначається як апроксимація відповідної гістограми. Для такого процесу сталість інформації $S \in$ максимальною і в цих умовах бажано приймати статистичні рішення про джерело інформації. Доцільно для стаціонарного процесу прирівняти $S$ до одиниці. Якщо стаціонарність процесу порушується, то сталість інформації повинна бути меншою одиниці незалежно від виду нестаціонарності. На практиці закони розподілу параметра $x$ для нестаціонарних процесів не 
визначають, якщо метою є прийняття рішення. Як правило, статистичну обробку проводять на інтервалах стаціонарності цього параметру. 3 математичної точки зору для нестаціонарного процесу також можна побудувати гістограму для $x$ i далі апроксимувати їі математичною функцією $p_{n s}(x)$ з заданою довірчою ймовірністю. Зрозуміло, що це потребує збільшення об'єму вибірки.

Отже, сталість інформації будемо обчислювати за фрормулою

$$
S=1-\frac{\Delta I}{I},
$$

де $I$ - кількість інформації для нестаціонарного випадку;

$\Delta I$ - максимальне змінювання кількості інфрормації $I$ в нестаціонарних умовах.

Вважаємо, що $\Delta I<I$, інакше втрачається фрізичний зміст сталості. Якщо $\Delta I=0$, то $S=1$, тобто в цьому випадку досягається найбільше значення сталості інформації. Це можливо, якщо випадковий процес був стаціонарним і залишився таким. Нестаціонарність приводить до розширення щільності ймовірностей $p(x)$ випадкової величини $x$ і таким чином ентропія $H_{x}$ або невизначеність неперервної випадкової величини $x$ збільшується. Якщо $p_{s}(x)$ - щільність ймовірностей випадкової величини $x$ для стаціонарного випадку, а $p_{n s}(x)$ - для нестаціонарного випадку, то сталість інформації визначимо наступним чином

$$
S=1-\frac{\Delta I}{I}=1-\left|\frac{\int_{-\infty}^{\infty} p_{n s}(x) \log _{2} p_{n s}(x) d x-\int_{-\infty}^{\infty} p_{s}(x) \log _{2} p_{s}(x) d x}{\int_{-\infty}^{\infty} p_{n s}(x) \log _{2} p_{n s}(x) d x}\right|
$$

Співвідношення (3) є моделлю сталості інформації, яка залежить від законів розподілу параметрів стаціонарного і нестаціонарного процесів. Нехай таким параметром $€$ прогин MC $x$, а його щільність ймовірностей описується гауссівським законом для обох видів процесів. В нестаціонарних процесах математичне очікування прогину та його дисперсія $€$ випадковими фрункціями часу. Тренд, що обумовлений часовою залежністю математичного очікування прогину, можна усунути. Отже, доцільно дослідити вплив дисперсії нестаціонарного процесу на сталість інформації $S$ при однакових математичних очікуваннях обох процесів, які при моделюванні прогинів МС прийняті 40 мм. Середньоквадратичне відхилення прогину стаціонарного процесу в першому випадку становило 3 мм, а в другому випадку - 10 мм. Зазначене відхилення $\sigma$ для нестаціонарного процесу коливалось в межах до 20 мм. Залежність сталості інформації від $\sigma$ для першого випадку (малі флуктуації прогину стаціонарного процесу) приведена на рис. 1.

Як і очікувалось, зі збільшенням середньоквадратичного значення прогину в нестаціонарному процесі при малих фрлуктуаціях стаціонарних прогинів сталість інфрормації істотно зменшується, якщо фрлуктуації початкового стаціонарного процесу, що потім згідно 3 моделлю перетворюється в нестаціонарний, є малими (перший випадок). При збільшенні дисперсії цих 
фрлуктуацій (другий випадок) сталість інформації зменшується, але не так значно (рис. 2). Отже, дисперсія початкового стаціонарного процесу впливає на сталість інформації. Це обумовлено припущенням, що сталість інформації для будь-якого стаціонарного процесу дорівнює одиниці, оскільки інформаційна стабільність стаціонарних процесів є високою [11].

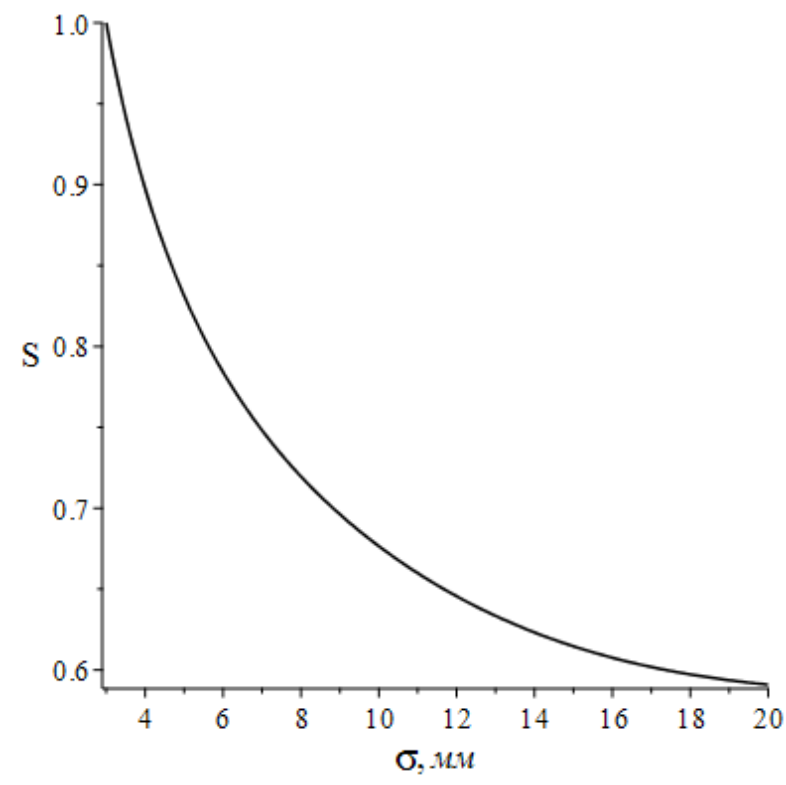

Рис. 1. Залежність сталості інформації від середньоквадратичного значення прогину при малих фрлуктуаціях стаціонарних прогинів

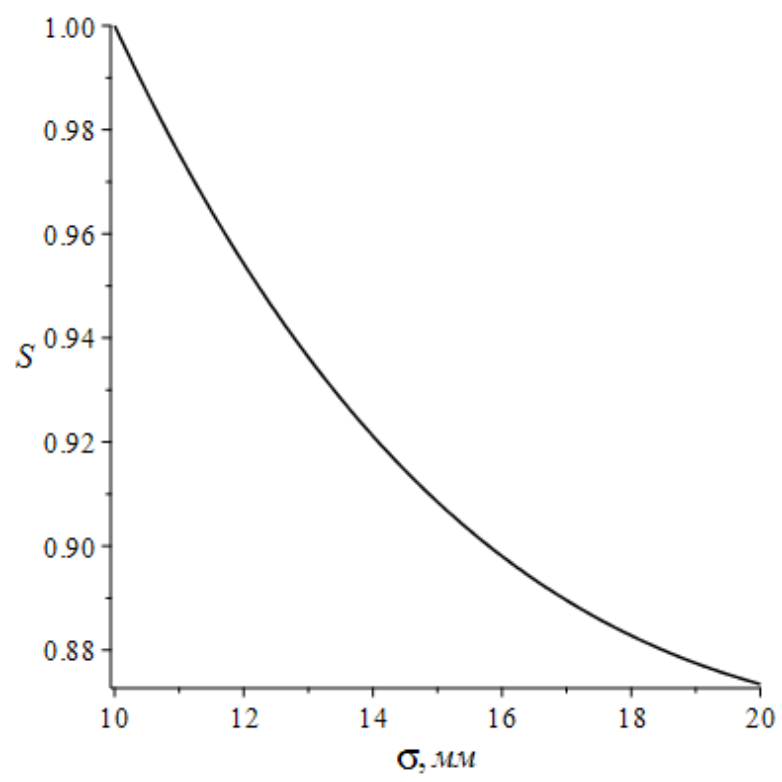

Рис. 2. Залежність сталості інформації від середньоквадратичного значення прогину при великих фрлуктуаціях стаціонарних прогинів

Відзначимо, що модель і метод оцінки сталості інформації розглядались не з точки зору їі існування, а з точки зору застосування до оцінки стану 
технічного об'єкту, причому сталість самих алгоритмів інформаційної системи не розглядалась. Детальний аналіз подібної сталості приведено в [12].

\section{2. Інформаційна технологія визначення сталості інформації}

Для оцінки сталості інформації використовується інформаційна технологія, що ґрунтується на етапах:

1) визначення параметрів стаціонарного процесу, насамперед, дисперсії параметру, що вимірюється; такий процес може існувати на окремих часових інтервалах або при окремих режимах роботи технічного об'єкту;

2) отримання щільності ймовірностей параметру для стаціонарного і нестаціонарного процесів, для чого необхідно набрати достатній об’єм вибірки;

3) розрахунок інформації джерела повідомлень через ентропію за формулою (1);

4) визначення сталості інформації за фрормулою (3).

Для реалізації даної інформаційної технології було створено графічний інтерфейс користувача (рис. 3) на мові програмування $\mathrm{C}++$, який дозволяє вираховувати сталість інформації за формулою (3). У лівій частині інтерфейсу розміщується графік щільності розподілу функції деякого параметру (у даному випадку прогину мосту) за результатами статистичної обробки багатьох реалізацій стаціонарного та нестаціонарного процесів (за вибором користувача). У правій частині інтерфейсу знаходиться поле для введення користувачем номеру експерименту, який потрібно аналізувати. У нижній частині інтерфейсу після натискання кнопки «Вибрати номер експерименту» виводиться значення показника сталості інформації.

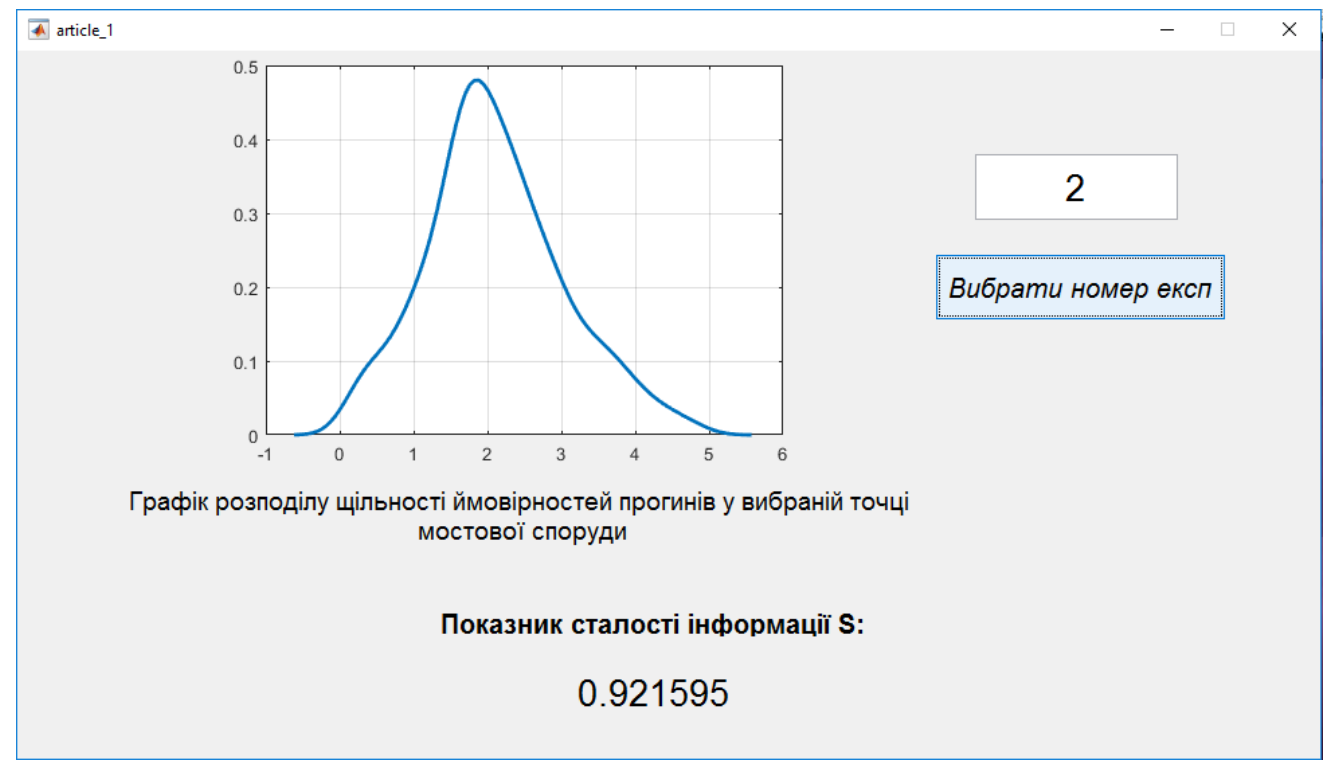

Рис. 3. Графічний інтерфейс користувача для оцінки сталості інформації

\section{Висновки}

В статті запропоновано модель і метод чисельного визначення сталості інформації (показника сталості) в умовах нестаціонарності прогинів мостової споруди. Метод і модель є універсальними і можуть використовуватись для 
будь-якого технічного об'єкту, стан якого потрібно визначити при дистанційному контролі. Замість прогинів в цьому випадку можуть використовуватись інші параметри, наприклад, тиск, напруга, сила. Опорним для визначення сталості інфрормації $€$ деякий стаціонарний процес, що описує поведінку важливого параметру технічного об'єкту. Дисперсія цього процесу впливає на чисельне значення показника сталості інформації. Найбільші значення показника досягаються при малій дисперсії стаціонарного процесу, який для даного об'єкту може бути зафріксованим у деякому режимі чи кожного разу визначатись перед проведенням оцінки сталості інформації. Порівнювати сталість інформації для різних технічних об'єктів, наприклад, двох різних і навіть близьких за конструкцією мостів некоректно. В статті запропоновано модель і метод визначення сталості інформації не з точки зору ії існування, а з точки зору застосування до оцінки стану технічного об'єкту.

\section{Список літератури}

1. Споруди транспорту. Мости та труби. Навантаження і впливи: ДБН В.1.2 - 15:2009. - [Чинний від 2009-11-11]. К.: Мінрегіонбуд України, 2009. - 66 с. - (Державні будівельні норми України).

2. Measurement of the Bridge Surface Deflections Using Near-Field Amplitude of Secondary Radiators System / [O. V. Poliarus, Y. O. Poliakov, A. V. Lebedynskyi та ін.]. // Advances in Science, Technology and Engineering Systems Journal. 2017. - №6. - C. 217-224.

3. Poliarus O. V. Detection of landmarks by autonomous mobile robots using camera-based sensors in outdoor environments / O. V. Poliarus, Y. O. Poliakov, A. V. Lebedynskyi. // IEEE Sensors Journal. - 2021. - №10. - C. 11443-11450.

4. Fuchs C. Information Technology and Sustainability in the Information Society / Christian Fuchs. // International Journal of Communication. - 2017. - №11. - C. 2431-2461.

5. Machado M. C. Sustainability in information technology: an analysis of the aspects considered in the model COBIT / M. C. Machado, H. J. Flavio, F. A. Sobra. // JISTEM J. Inf. Syst. Technol. Manag.. - 2017. - №14. - C. 154-178.

6. Mobbs P. A practical guide to sustainable IT [Електронний ресурс] / Paul Mobbs // APC. - 2012. - Режим доступу до ресурсу: https://www.apc.org/en/pubs/practical-guide-sustainable-it.

7. Nolin J. Sustainable information and information science / Jan Nolin. // Information research (an international electronic journal). - 2010. - №15. - C. 13681613

8. Piotrowicz W. Sustainability - a new dimension in information systems evaluation / W. Piotrowicz, R. Cuthbertson. // Journal of Enterprise Information Management. - 2009. - №22. - C. 492-503.

9. Стійкість систем [Електронний ресурс]. - 2012. - Режим доступу до pecypcy: https://uk.wikipedia.org/wiki/Стійкість_систем.

10. Шеннон К. Э. Работы по теории информации и кибернетике / К. Э. Шеннон. - Москва: Изд-во иностранной литературы, 1963. - 830 с.

11. Kadota T. T. On the Information Stability of Stationary Ergodic Processes / Kadota. // SIAM Journal on Applied Mathematics. - 1974. - №26. - C. 176-182.

12. Information-Theoretic Analysis of Stability and Bias of Learning Algorithms / [M. Raginsky, A. Rakhlin, M. Tsao та ін.]. // 2016 IEEE Information Theory Workshop (ITW). - 2016. - C. 135-167. 


\section{References}

1. Sporudy transportu. Mosty ta truby. Navantazhennya i vplyvy: DBN V.1.2 15:2009. - [Chynnyy vid 2009-11-11]. K.: Minrehionbud Ukrayiny, 2009. - 66 s. (Derzhavni budivel'ni normy Ukrayiny).

2. Measurement of the Bridge Surface Deflections Using Near-Field Amplitude of Secondary Radiators System / [O. V. Poliarus, Y. O. Poliakov, A. V. Lebedynskyi ta in.]. // Advances in Science, Technology and Engineering Systems Journal. 2017. - \#6. - S. 217-224.

3. Poliarus O. V. Detection of landmarks by autonomous mobile robots using camera-based sensors in outdoor environments / O. V. Poliarus, Y. O. Poliakov, A. V. Lebedynskyi. // IEEE Sensors Journal. - 2021. - \#10. - S. 11443-11450.

4. Fuchs S. Information Technology and Sustainability in the Information Society / Shristian Fuchs. // International Journal of Communication. - 2017. - \#11. S. 2431-2461.

5. Machado M. C. Sustainability in information technology: an analysis of the aspects considered in the model COBIT / M. C. Machado, H. J. Flavio, F. A. Sobra. // JISTEM J. Inf. Syst. Technol. Manag.. - 2017. - \#14. - C. 154-178.

6. Mobbs R. A practical guide to sustainable IT [Elektronnyy resurs] / Raul Mobbs I/ APC. - 2012. - Rezhym dostupu do resursu: https://www.apc.org/en/pubs/practical-guide-sustainable-it.

7. Nolin J. Sustainable information and information science / Jan Nolin. // Information research (an international electronic journal). - 2010. - \#15. - S. 13681613.

8. Piotrowicz W. Sustainability - a new dimension in information systems evaluation / W. Piotrowicz, R. Cuthbertson. // Journal of Enterprise Information Management. - 2009. - \#22. - S. 492-503.

9. Stiykist' system [Elektronnyy resurs]. - 2012. - Rezhym dostupu do resursu: https://uk.wikipedia.org/wiki/Stiykist'_system.

10. Shennon K. Je. Raboty po teorii informacii i kibernetike / K. Je. Shennon. Moskva: Izd-vo inostrannoj literatury, 1963. - $830 \mathrm{~s}$.

11. Kadota T. T. On the Information Stability of Stationary Ergodic Processes / Kadota. // SIAM Journal on Applied Mathematics. - 1974. - \#26. - S. 176-182.

12. Information-Theoretic Analysis of Stability and Bias of Learning Algorithms / [M. Raginsky, A. Rakhlin, M. Tsao ta in.]. // 2016 IEEE Information Theory Workshop (ITW). - 2016. - S. 135-167.

Надійшла до редакції 20.05.2021, розглянута на редколегії 20.05.2021

\section{Метод, модель и информационная технология определения устойчивости информации при дистанционном контроле состояния технических объектов}

В информационных технологиях целесообразным является определение устойчивости информации, то есть способности получать точную информацию в изменяющихся условиях. В таких обстоятельствах входные процессы описываются нестационарными случайными процессами, у которых дисперсия и математическое ожидание меняются с течением времени. В статье предложена модель и метод численного определения устойчивости 
инфрормации (показателя устойчивости) в условиях нестационарности входных процессов, а также информационная технология, позволяющая наглядно получать сведения об устойчивости конкретной информации в зависимости от решения о состоянии технического объекта. Для примера в качестве такого объекта выбрано мостовую сооружение, а информация фрормируется на основе сигналов, описывающих прогибы нижней части сооружения.

В статье проанализированы плотности вероятностей стационарных и нестационарных процессов прогиба мостовых сооружений для различных видов нагрузок. В большинстве случаев плотность вероятностей обоих процессов описывается гауссовским законом. Была найдена зависимость устойчивости информации от среднеквадратического значения прогиба мостовых сооружений, а также зависимость устойчивости информации от среднеквадратического значения прогиба при больших фрлуктуациях стационарных прогибов.

Был разработан графический интерфейс пользователя, который позволяет наглядно увидеть график распределения плотности вероятностей прогиба в некоторой точке мостового сооружения, а также определить численно показатель устойчивости информации, который по определению может колебаться от 0 до 1. Наличие минимального значения показателя можно трактовать как отсутствие устойчивости информации, а максимальное значение показателя устойчивости - как наличие устойчивости информации.

Сделаны выводы, что данный метод является универсальным и может использоваться для различных технических объектов в условиях нестационарности. После анализа графиков зависимости показателя устойчивости и среднеквадратичное прогиба было обнаружено, что с увеличением среднеквадратического значения прогиба для нестационарного процесса при малых фрлуктуациях стационарных прогибов устойчивость информации существенно уменьшается.

Ключевые слова: информационная технология; дистанционный контроль состояния технических объектов; устойчивость информации; мостовые сооружения; нестационарные процессы.

\section{Method, model and information technology for determining the information sustainability during remote monitoring the technical objects state}

In information technology, it is expedient to determine the sustainability of information, that is, the ability to receive accurate information in changing conditions. In such circumstances, input processes are described by non-stationary random processes. The article proposes a model and a method for the numerical determination of the sustainability of information (sustainability index) under conditions of nonstationarity of input processes, as well as information technology that allows you to visually obtain information about the constancy of specific information depending on the decision on the state of a technical object. For example, a bridge structure was chosen as such an object, and the information is formed on the basis of signals describing the deflections of the lower part of the structure. 
In the article the probability densities of stationary and non-stationary processes of deflection of bridge structures for various types of loads were analyzed.

The dependence of the sustainability of information on the root-mean-square value of the deflection of bridge structures was found, as well as the dependence of the sustainability of information on the root-mean-square value of the deflection at large fluctuations of stationary deflections.

A graphical user interface was developed, which allows you to see the graph of the distribution of the probability density of deflection at a certain point of the bridge structure visually, as well as to numerically determine the index of information sustainability, which, by definition, can vary from 0 to 1 . The presence of a minimum value of the index can be interpreted as the lack of sustainability of information and the maximum value of the sustainability index can be interpreted as the presence of information sustainability.

It is concluded that this method is universal and can be used for various technical objects under non-stationary conditions. After analyzing the graphs of the dependence of the sustainability index and the root-mean-square deflection, it was found that with an increase of the root-mean-square value of the deflection for a nonstationary process at small fluctuations of stationary deflections, the sustainability of information significantly decreases.

Keywords: information technology; remote control of technical objects state; information sustainability; bridge structures; non-stationary processes.

\section{Відомості про авторів:}

Полярус Олександр Васильович - д.Т.н., професор, завідувач кафедри метрології та безпеки життєдіяльності, Харківський національний автомобільнодорожній університет, Харків, Україна, poliarus.kharkov@ukr.net, ORCID 00000002-8023-5189.

Лебединський Андрій Володимирович - аспірант кафедри метрології та безпеки життєдіяльності, Харківський національний автомобільно-дорожній університет, Харків, Україна, zoops0mania@gmail.com, ORCID 0000-0002-50868209.

\section{About the authors:}

Poliarus Oleksandr Vasylovych - Doctor of Engineering Sciences, Professor, Head of the Department of Metrology and Life Safety, Kharkiv National Automobile and Highway University, Kharkiv, Ukraine, poliarus.kharkov@ukr.net, ORCID 0000-0002-8023-5189.

Lebedynskyi Andrii Volodymyrovych - Post-Graduate Student of the Department of Metrology and Life Safety, Kharkiv National Automobile and Highway University, Kharkiv, Ukraine, zoops0mania@gmail.com, ORCID 0000-0002-50868209. 